IRA-International Journal of Technology \& Engineering

ISSN 2455-4480; Vol.04, Issue 01 (2016)

Institute of Research Advances

http://research-advances.org/index.php/IRAJTE

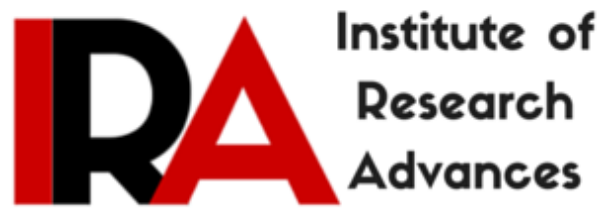

\title{
Linear Polarized Non Uniform Shaped Patch Antenna
}

\author{
${ }^{1}$ Adnan Affandi , ${ }^{2}$ Navin Kasim , ${ }^{3}$ Talal Hamdan Hamad Althebiani \\ ${ }^{\mathbf{1 , 2 , 3}}$ Electrical and Computer Engineering Department, \\ King Abdul Aziz University, P.O. BOX: 80204, Jeddah 21589.
}

DOI: http://dx.doi.org/10.21013/jte.v4.n1.p1

\section{How to cite this paper:}

Affandi, A., Kasim, N., \& Althebiani, T. (2016). Linear Polarized Non Uniform Shaped Patch Antenna. IRA-International Journal of Technology \& Engineering (ISSN 24554480), 4(1). doi:http://dx.doi.org/10.21013/jte.v4.n1.p1

(C) Institute of Research Advances

(c) EY-NC

This works is licensed under a Creative Commons Attribution-Non Commercial 4.0 International License subject to proper citation to the publication source of the work.

Disclaimer: The scholarly papers as reviewed and published by the Institute of Research Advances (IRA) are the views and opinions of their respective authors and are not the views or opinions of the IRA. The IRA disclaims of any harm or loss caused due to the published content to any party. 


\section{ABSTRACT}

In this paper a Non Uniform shaped patch antenna has been designed, simulated and optimized. Microstrip patch antennas with linear based on general requirement network have been investigated. All of the singles and arrays patch antennas are implemented in microstrip transmission line. Single patch non uniform antenna has also been investigated with enhancement factor i.e parasitic elements to investigate the parameter changes. All the designs are simulated and analyzed using Advanced Design System (ADS) software.

Keywords: Non-uniform, linear and Circular polarization; Antenna array; ADS

\section{Introduction}

Non Uniform shaped patch antenna has been designed, simulated and optimized as shown in figure 1.1. It has also been attempted to increase important parameters of the antenna using the parasitic effect which actually acts as an enhancement factor. The design specification is given in table 1.1

\section{TABLE 1.1 Non Uniform Shaped Patch Antenna Design Specifications}

\begin{tabular}{|c|c|}
\hline Frequency & $27.7 \mathrm{GHz}$ \\
\hline Substrate & Alumina \\
\hline Dielectric Constant $\varepsilon r$ & 9.6 \\
\hline Substrate Height & $25 \mathrm{mil}$ \\
\hline
\end{tabular}

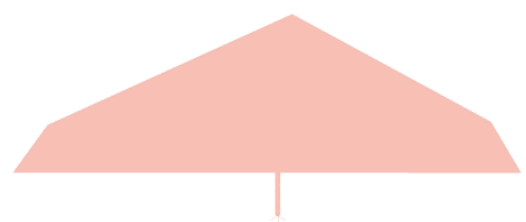

Figure 1.1 Non-uniform shaped patch antenna

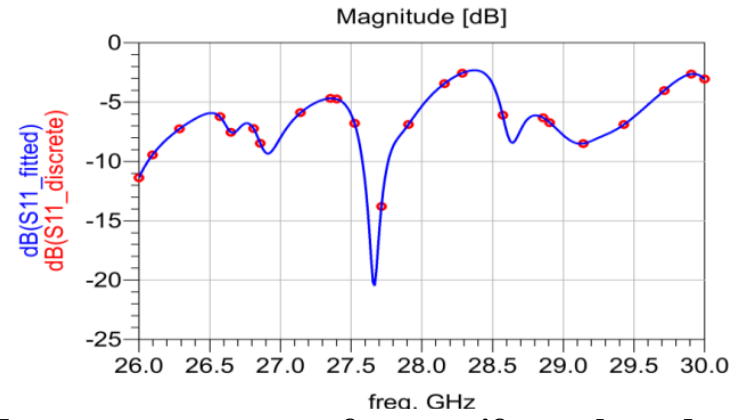

Figure 1.2 Frequency response of non-uniform shaped patch antenna

Figure 1.2 shows a return loss of $-20.47 \mathrm{~dB}$ at $27.67 \mathrm{GHz}$. We can also see that the response has narrow bandwidth between $27.58 \mathrm{GHz}$ and $27.76 \mathrm{GHz}$ with reflection less than $-10 \mathrm{~dB}$. 
Thus the bandwidth is $0.2 \mathrm{GHz}$. This antenna is an excellent linearly polarized antenna as can be seen in figure 1.3(a).The 3D radiation pattern which is shown in figure 1.4 in logarithmic and linear scales indicates that it is almost uniform, while table 1.2 represents this antenna calculated parameters.

Linear Polarization

E_co E_cross

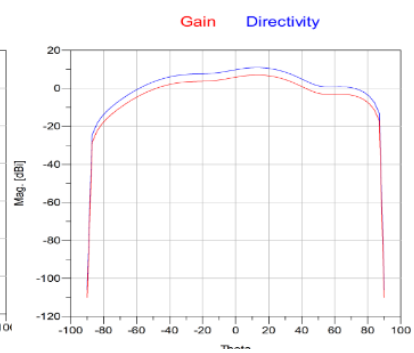

(a)

(b)

Figure 1.3 2D Radiation pattern of non-uniform shaped patch antenna

(a) Co and Cross Polarization (b) Gain and Directivity

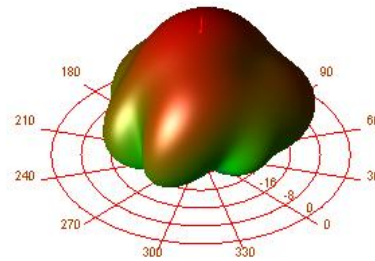

(a)

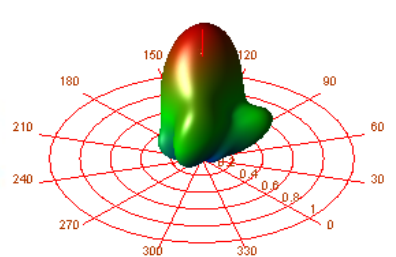

(b)

Figure 1.4 3D Radiation pattern of non-uniform shaped patch antenna (a) Logarithmic scale (b) Linear scale

TABLE 1.2 Antenna Parameters of Non-Uniform Shaped Patch Antenna

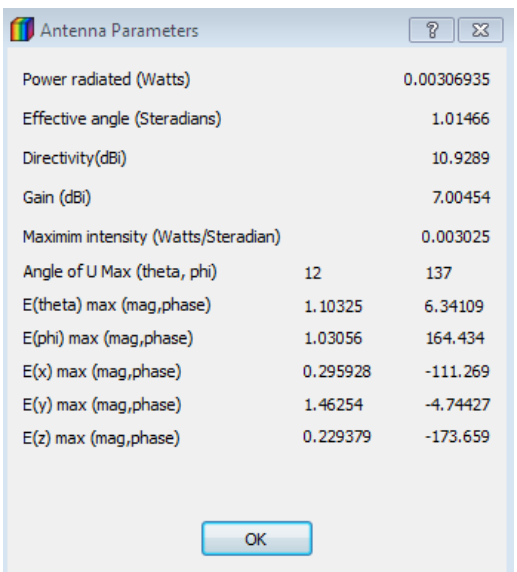




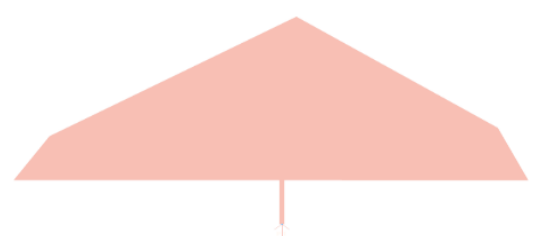

Figure 1.5 The Optimized non-uniform shaped patch antenna

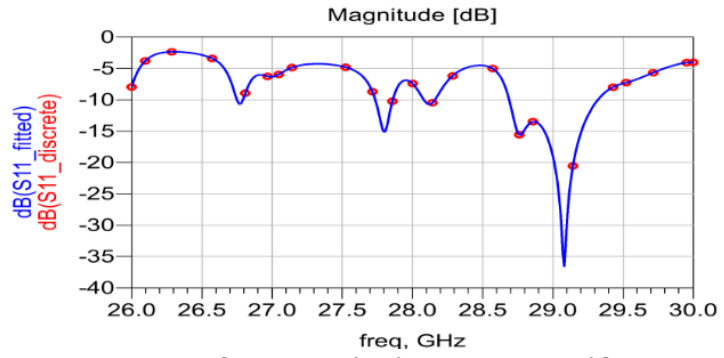

Figure 1.6 Frequency response of the optimized non-uniform shaped patch antenna

It is observed from figure 1.6 that the non-uniform shaped antenna operates as a dual bandwidth at 27.8 $\mathrm{GHz}$ and $29.08 \mathrm{GHz}$ with return less of $-15.11 \mathrm{~dB}$ and -36.64 have been obtained respectively. A high gain of $10.45 \mathrm{~dB}$ and $7.2 \mathrm{~dB}$ have been achieved respectively. This proposed antenna is suitable for Ka band application specially in satellite communication. The 3D radiation pattern which is shown in figure 1.8 indicates that it is almost uniform and good linearly polarized as can be seen in figure 1.7(a), while table 1.3 represents this antenna calculated parameters. This antenna is optimized and narrow bandwidths.

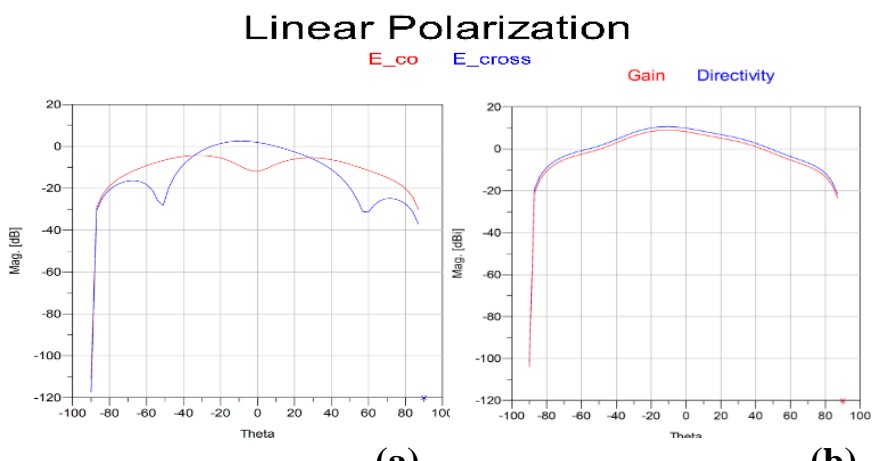

(a)

(b)

Figure 1.7 2D Radiation pattern of optimized non-uniform shaped patch antenna
(a) Co and Cross Polarization (b) Gain and Directivity

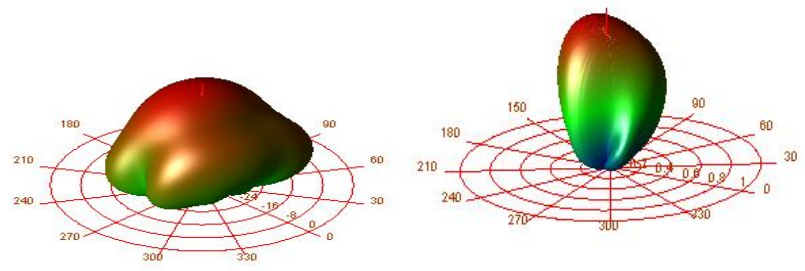

(a)

(b)

Figure 1.8 3D Radiation pattern of the optimized non-uniform shaped patch antenna

(a) Logarithmic scale (b) Linear scale 
TABLE 1.3 Antenna Parameters of the Optimized Non-Uniform Shaped Patch Antenna

\begin{tabular}{|c|c|c|}
\hline (11) Antenna Parameters & & 8 \\
\hline Power radiated (Watts) & & 0.00488039 \\
\hline Effective angle (Steradians) & & 0.846478 \\
\hline Directivity(dBi) & & 11.7159 \\
\hline Gain (dBi) & & 10.4676 \\
\hline Maximim intensity (Watts/Steradian) & & 0.00576552 \\
\hline Angle of $U$ Max (theta, phi) & 11 & 147 \\
\hline$E$ (theta) max (mag,phase) & 1.23899 & 13.2174 \\
\hline E(phi) max (mag,phase) & 1.67601 & 163.02 \\
\hline$E(x) \max$ (mag,phase) & 0.514 & -103.497 \\
\hline$E(y) \max$ (mag, phase) & 2.00599 & -7.41964 \\
\hline$E(z) \max$ (mag,phase) & 0.23641 & -166.783 \\
\hline OK & & \\
\hline
\end{tabular}

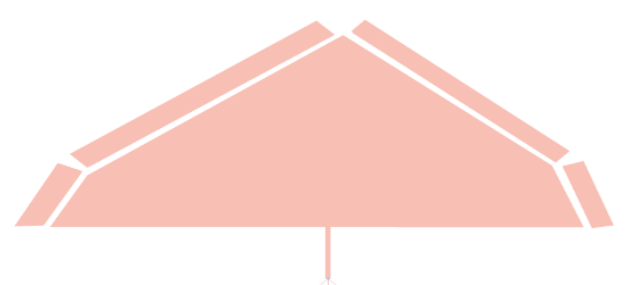

Figure 1.9 Non-uniform shaped patch antenna with parasitic elements

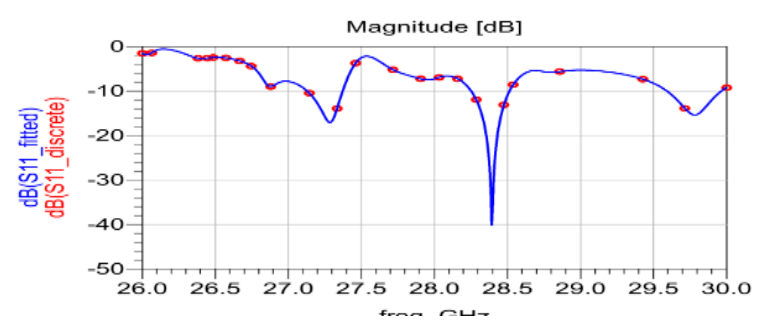

Figure 1.10 Frequency response of non-uniform shaped patch antenna with parasitic elements

Figure 1.9 shows a non-uniform shaped patch antenna with parasitic elements has been designed and simulated to improve the antenna parameters. It is observed from figure 1.10 that the non-uniform shaped antenna with parasitic elements operates as a multiple bandwidth at $27.3 \mathrm{GHz}, 28.4 \mathrm{GHz}$ and $29.8 \mathrm{GHz}$ with return less of $-17,-40.2$ and $\quad-15.4 \mathrm{~dB}$ have been obtained respectively. A maximum gain of 11.17 has been achieved .This proposed antenna is suitable for Ka band applications.

The 3D radiation pattern which is shown in figure 1.12 indicates that it is almost uniform and good linearly polarized as can be seen in figure 1.11(a), while table 1.4 represents this antenna calculated parameters.

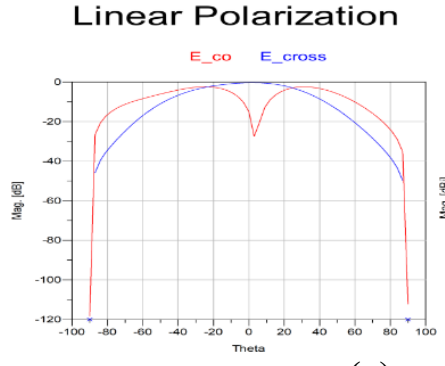

(a)

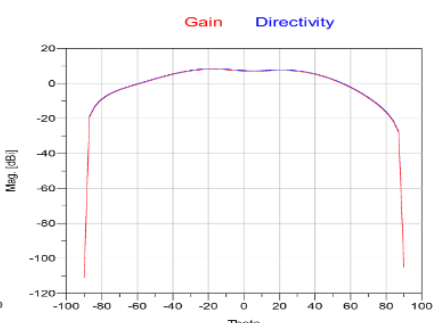

(b) 
Figure 1.11 2D Radiation pattern of non-uniform shaped patch antenna with parasitic elements (a) Co and Cross Polarization (b) Gain and Directivity

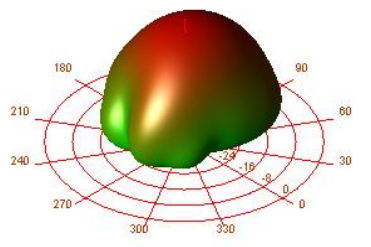

(a)

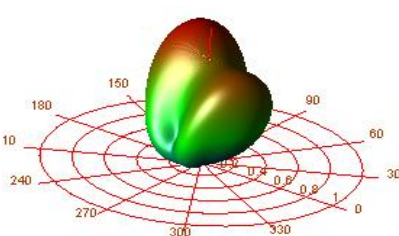

(b)

Figure 1.12 3D Radiation pattern of non-uniform shaped patch antenna with parasitic elements (a) Logarithmic scale (b) Linear scale

TABLE 1.4 Antenna Parameters of Non-Uniform Shaped Patch Antenna with Parasitic Elements

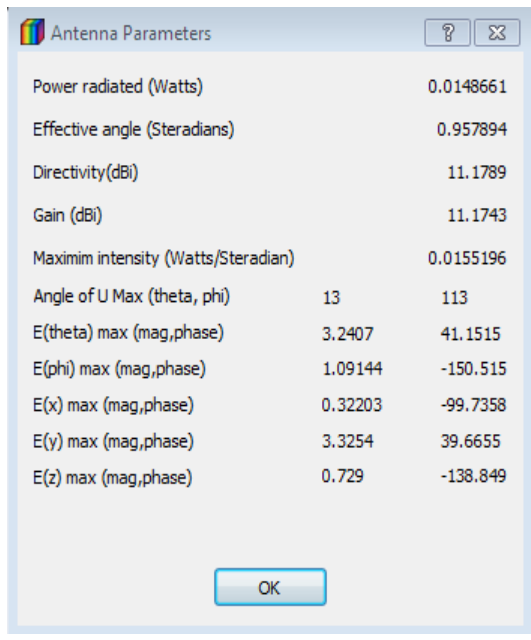

TABLE 1.5 Comparison of Performance Parameters for Non-Uniform Shaped Patch Antenna Geometries

\begin{tabular}{|c|c|c|c|c|c|}
\hline Patch Antenna Type & $\begin{array}{c}\text { (S11<-10dB) } \\
\mathrm{BW} \mathrm{GHz}\end{array}$ & $\begin{array}{c}\text { Return Loss } \\
\mathrm{dB}\end{array}$ & $\begin{array}{c}\text { Gain } \\
\mathrm{dB}\end{array}$ & $\begin{array}{c}\text { Directivity } \\
\mathrm{dB}\end{array}$ & Remark \\
\hline Single Element & 0.2 & -20.46 & 7 & 10.92 & \\
\cline { 2 - 6 } & 0.8 & -36.64 & 10.46 & 11.71 & $\begin{array}{c}\text { after } \\
\text { optimization }\end{array}$ \\
\hline $\begin{array}{c}\text { with parasitic } \\
\text { elements }\end{array}$ & 0.88 & -40.24 & 11.17 & 11.17 & $\begin{array}{c}\text { Multi } \\
\text { Bandwidth }\end{array}$ \\
\hline
\end{tabular}

The above summary table 1.5 shows the improvement in the antenna gain as well as directivity by using optimization and the parasitic elements. This antenna has multi bandwidth which is suitable for Ka band application specially in satellite communication. 


\section{Non Uniform Shaped Patch Antenna Array}

Another type of non-uniform shaped patch antenna has been used to generate arrays in order to improve the antenna parameters. As shown in figures below the designs combine between $(2,4,8)$ elements of the non-uniform shaped patch antenna array to measure the main criteria and compares the results.

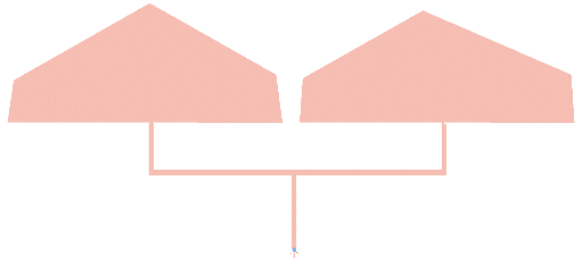

Figure 2.1 Two elements non-uniform shaped patch antenna array

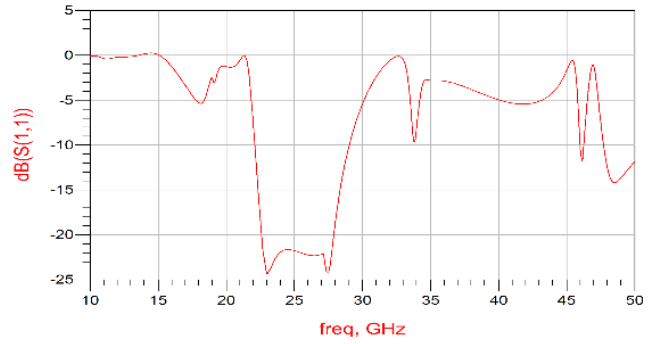

(Corporate Feed)

Feed)

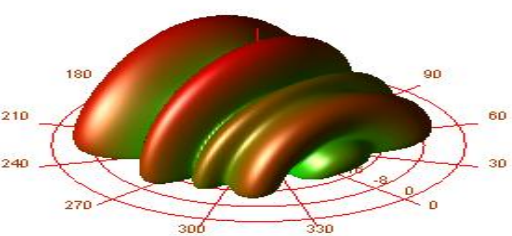

Figure 2.3 3D Radiation pattern of the two elements non-uniform shaped patch antenna array (Corporate Feed)

TABLE 2.1 Antenna Parameters of the Two Elements Non-Uniform Shaped Patch Antenna Array (Corporate Feed

\begin{tabular}{|c|c|c|}
\hline (i) Antenna Parameters & & \begin{tabular}{ll|l}
8 & 23
\end{tabular} \\
\hline Power radiated (Watts) & & 0.0096949 \\
\hline Effective angle (Steradians) & & 1.09736 \\
\hline Directivity(dBi) & & 10.5886 \\
\hline Gain (dBi) & & 9.91808 \\
\hline Maximim intensity (Watts/Steradian) & & 0.00883476 \\
\hline Angle of $U$ Max (theta, phi) & 39 & 159 \\
\hline$E$ (theta) $\max$ (mag, phase) & 1.56186 & 142.545 \\
\hline E(phi) max (mag, phase) & 2.05359 & -89.6092 \\
\hline$E(x) \max$ (mag,phase) & 0.895748 & 2.99475 \\
\hline$E(y) \max$ (mag,phase) & 2.21092 & 99.3285 \\
\hline$E(z) \max$ (mag,phase) & 0.982908 & -37.4552 \\
\hline ok & & \\
\hline
\end{tabular}




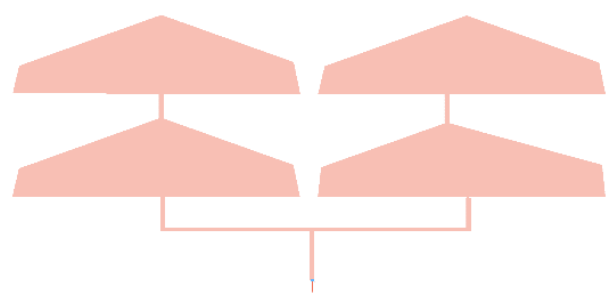

Figure 2.4 Four elements non-uniform shaped patch antenna array (Corporate-Series Feed)

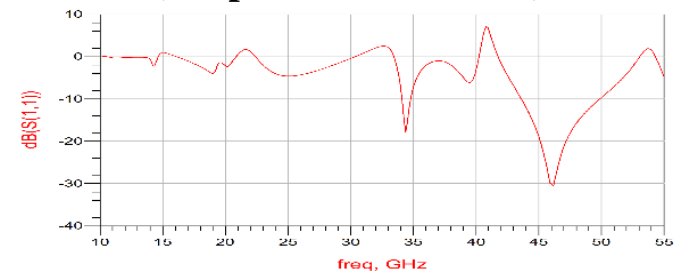

Figure 2.5 The return loss of the four elements non-uniform shaped patch antenna array (Corporate-Series Feed)

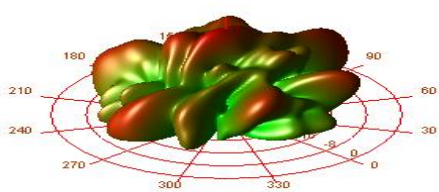

Figure 2.6 3D Radiation pattern of the four elements non-uniform shaped patch antenna array (Corporate-Series Feed)

TABLE 2.2 Antenna Parameters of the Four Elements Non-Uniform Shaped Patch Antenna Array (Corporate-Series Feed)
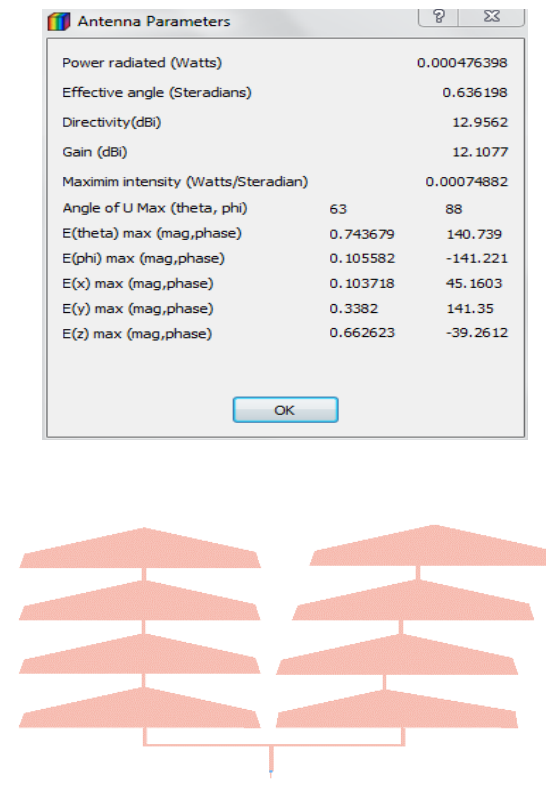

Figure 2.7 Eight elements non-uniform shaped patch antenna array (Corporate-Series Feed) 


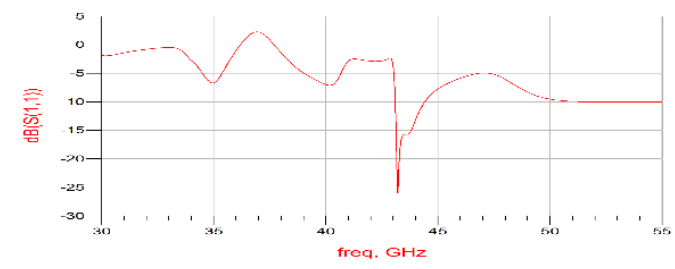

Figure 2.8 The return loss of the eight elements non-uniform patch antenna array (CorporateSeries Feed)

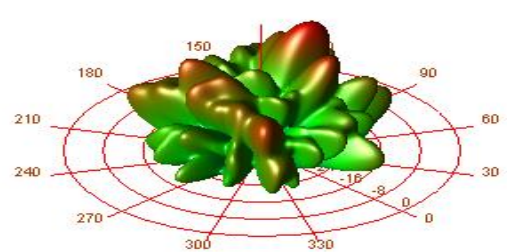

Figure 2.9 3D Radiation pattern of the eight elements non-uniform shaped patch antenna array (Corporate-Series Feed)

Table 2.3 Antenna parameters of The Eight Elements Non-Uniform Shaped Patch Antenna Array (Corporate-Series Feed)

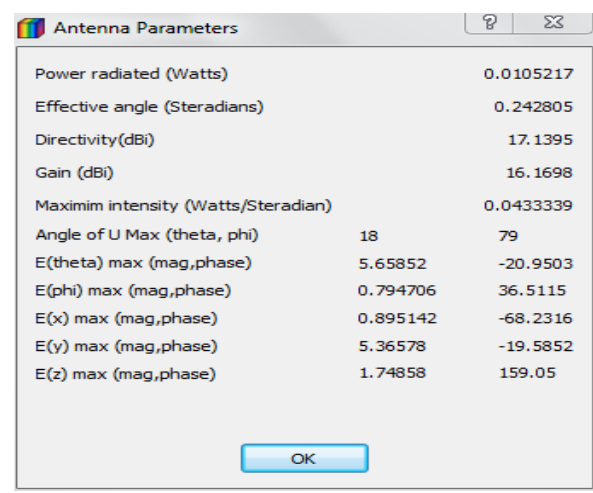

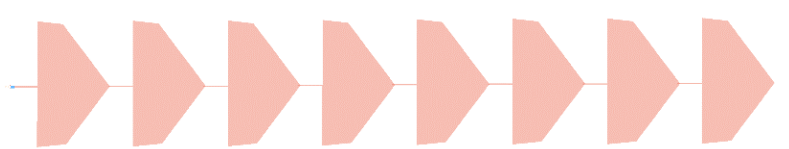

Figure 2.10 Eight elements non-uniform shaped patch antenna array (Series Feed)

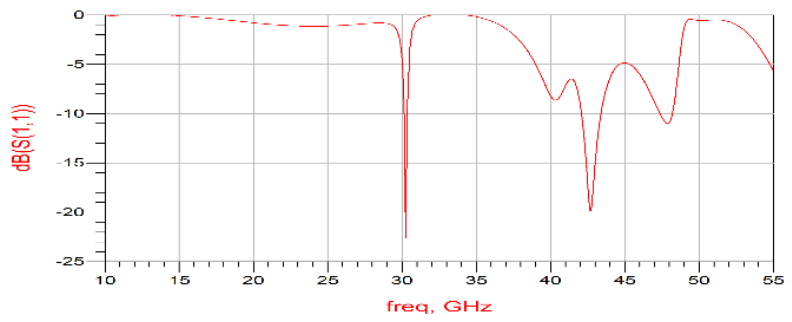

Figure 2.11 The return loss of the eight elements non-uniform shaped patch antenna array (Series Feed) 


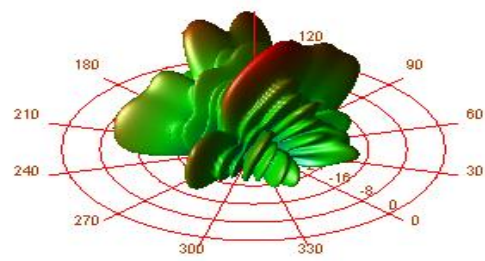

Figure 2.12 3D Radiation pattern of the eight elements non-uniform shaped patch antenna array (Series Feed)

TABLE 2.4 Antenna Parameters of The Eight Elements Non-Uniform Shaped Patch Antenna Array (Series Feed)

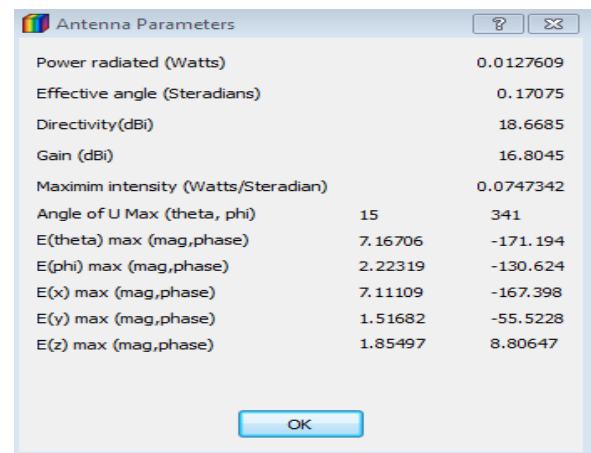

TABLE 2.5 Comparison of Performance Parameters of Non-Uniform Shaped Patch Antenna Arrays

\begin{tabular}{|c|c|c|c|c|c|c|}
\hline \multicolumn{2}{|c|}{ Patch Antenna Type } & $\begin{array}{c}\text { (S11 <-10dB) } \\
\text { BW GHz }\end{array}$ & $\begin{array}{c}\text { Return } \\
\text { Loss (dB) }\end{array}$ & $\begin{array}{c}\text { Gain } \\
\text { dB }\end{array}$ & $\begin{array}{c}\text { Directivi } \\
\text { ty dB }\end{array}$ & Remark \\
\hline $\begin{array}{c}\text { 2 Elements } \\
\text { (Corporate Feed) }\end{array}$ & 9.47 & -24.41 & 9.91 & 10.58 & $\begin{array}{c}\text { Multi } \\
\text { Bandwidth }\end{array}$ \\
\hline $\begin{array}{c}\text { 4 Elements } \\
\text { (Corporate-Series Feed) }\end{array}$ & 6.96 & -30.57 & 12.1 & 12.95 & $\begin{array}{c}\text { Dual } \\
\text { Bandwidth }\end{array}$ \\
\hline $\begin{array}{c}\mathbf{8} \\
\text { Element } \\
\mathbf{S}\end{array}$ & $\begin{array}{c}\text { Corporate- } \\
\text { Series Feed }\end{array}$ & 1.39 & -26.04 & 16.17 & 17.14 & \\
\cline { 2 - 7 } & Series Feed & 1.55 & -22.6 & 16.8 & 18.66 & $\begin{array}{c}\text { Multi } \\
\text { Bandwidth }\end{array}$ \\
\hline
\end{tabular}

\section{Conclusion}

As seen from the simulation result the non uniform shaped patched antenna reflected various changes in the antenna parameters.From above summary table 2.5 , we can observe clearly the relation between the number of the array and the gain is proportional whereas the increasing the number of elements, the gain will increase also the directivity will increase. On the other hand, the bandwidth decrease if the number of the elements increased. Also it has to be taken in consideration the frequency shifting because of the elements number. For that, the antenna gain and directivity shows high for eight elements array with little bit improvement for eight elements series feed as indicated in the above table. The major applications for 
such extremely high frequency range for this kind of antenna is Astronomy and Remote Sensing application.

\section{Acknowledgement}

The authors acknowledge Engineering Faculty in King AbdulAziz University (KAU), Saudi Arabia, for supporting the research.

\section{References}

[1] C. Balanis "Antenna Theory Analysis and Design", second edition, John Wiley, 1997.

[2] R. Garg, P. Bhartia, I. Bahk, A. Ittipiboor, "Microstrip Antenna Design Handbook." Artech House, 2001.

[3] Soonsoo Oh, Seongho Seo, Mikyoung Yoon,Changyoul Oh, Eungbae Kim,and Youngsik Kim, "A Broadband Microstrip Antenna Array for LMDS Applications", microwave and optical technology letters, vol. 32, no.1, 2002

[4] James, J.R., and P.S. Hall, " Handbook of Microstrip Antennas", Vol. 1, London: Peter Peregrines Ltd., 1989.

[5] Saunders, Simon R., “Antennas and Propagation for Wireless Communication Systems”, John Wiley \& Sons Ltd., October 2003.

[6] Newman, E.H., and Tulyathan, "Analysis of Microstrip Antennas Using Method of Moments," IEEE Trans. Antennas Propagation, Vol. AP-29, January 1981, pp.47-53.

[7] Jean-Francois Zurcher and Fred E.Gardiol, "Broadband Patch Antenna”, Artech house,Boston,1995.

[8] Y.T.Lo and S.W.Lee, "Antenna Handbook Theory, Application and Design”, Van Nostrand Renhold Company, New York, 1988.

[9] R.C. Johnson, “Antenna Engineering Handbook”, McGraw-Hill, New York, 1993.

[10] Y. Suzuki, N. Miyano, T. Chiba, "Circularly Polarised Radiation from Singly Fed EquilateralTriangular Microstrip Antenna," IEE Proceedings on Microwaves, Antennas and Propagation, vol. 134 , Issue. 2.

[11] Alpesh U. B. and Patrick, L. P. "“An Overview of Smart Antenna Technology for Wireless Communication”, Aerospace Conference. March 10-17, 2001. IEEE. 2000. 2/875 - 2/883.

[12] Pozar, D. M. ,“ Microwave Engineering”, 4th ed. Hoboken, N. J.: John Wiley \& Sons. 2012.

[13] Adnan Affandi, Navin Kasim, and Mubashshir Husain, "Converging Algorithm for Calculation of Elements Current That Include Effects of Mutual Coupling," International Refereed Journal of Engineering and Science (IRJES) Volume 2, Issue 3 (March 2013), pp. 43-53

[14]Navin Kasim, Shankar. D, Mahesh. A, Dr. T. S. Rukmini, "Gain Enhancement of Microstrip Patch Antenna with Concave Dielectric Lens for Wireless Broadband Communication," on Microwaves, Antenna, Propogation and Remote Sensing, ICMARS- 2009, 19th - 21st December Jodhpur. 
[15]. Adnan Affandi, Abdullah Dobaei, Navin Kasim "A Multi-Bands Circular Polarized of Series Triangular Microstrip Patch Antenna Array," Accepted To The 1st International Conference on Electrical Engineering and Applications (MIC-Electrical 2014)

[16]. Adnan Affandi, Abdullah Dobaei, Navin Kasim, "Rectangular Microstrip Patch Antenna Arrays with Inset for Cellular Phones Application), Accepted To The 1st International Conference on Electrical Engineering and Applications (MIC-Electrical 2014)

[17]. Adnan Affandi, Abdullah Dobaei, Navin Kasim, "A Multi-Bands Circular Polarized of Series Triangular Microstrip Patch Antenna Array), Accepted To The 1st International Conference on Electrical Engineering and Applications (MIC-Electrical 2014)

[18]. Adnan Affandi, Mubashshir Husain \& Navin Kasim, "Optimization for Spherical Phased Array Antenna," International Refereed Journal of Engineering and Science (IRJES), Volume 2, Issue 2 (February 2013), pp. 54-80. 